\title{
HARMONIC DOMAIN MODEL OF AN OPEN-LOOP CONTROLLED PWM CONVERTER
}

\author{
Malte John, Axel Mertens \\ Leibniz Universität Hannover, Institute for Drive Systems and Power Electronics
}

Abstract. An harmonic domain model is developed for open-loop controlled voltage source inverters, which provides the steady-state solution for integer multiples of the fundamental frequency. The convolution of the switching function spectrum with the converter currents and voltages is used to describe the coupling of the AC side and the DC side. The modeling is based on a single phase leg and is extended to a single-phase and a three-phase voltage source inverter, which results in a non-linear algebraic equation system. For open-loop control the switching function is independent of the converter currents and voltages and the model is simplified to a linear equation system. This straightforward and fast model is verified by time domain simulations and experimental results. The modeling can be adapted to systems of coupled converters, which is presented for a back-to-back converter system showing the harmonic interaction of the connected subsystems.

Keywords: frequency-domain analysis, Power conversion harmonics

\section{CZESTOTLIWOŚCIOWY KONWERTER PWM ZE STEROWANIEM W OTWARTEJ PECTLI}

Streszczenie. Opracowano model $w$ domenie częstotliwości dla falowników napięcia sterowanych w otwartej pętli, który zapewnia rozwiązanie w stanie ustalonym dla całkowitych wielokrotności częstotliwości podstawowej. Splot spektrum funkcyjnego przetaczania z prądami i napięciami przemiennika stuży do opisania sprzężenia strony pradu przemiennego i prądu stałego. Modelowanie opiera się na pojedynczej fazie $i$ jest rozszerzone na falownik jednofazowy i trójfazowy, co skutkuje nieliniowym uktadem równań algebraicznych. W przypadku sterowania w otwartej pętli funkcja przełączania jest niezależna od prądów i napięć przeksztattnika, a model jest uproszczony do układu równań liniowych. Ten prosty i szybki model jest weryfikowany przez symulacje $w$ dziedzinie czasu $i$ wyniki eksperymentalne. Modelowanie może być dostosowane do systemów przekształtników sprzężonych, które przedstawiono dla systemu konwertera równoległego pokazującego harmoniczne oddziaływanie połaczonych podsystemów.

Słowa kluczowe: analiza w dziedzinie częstotliwości, harmoniczne konwersji mocy

\section{Introduction}

The accurate assessment of the harmonic behavior of power electronic converters is required during various design steps, e.g. filter design, capacitor lifetime estimation, converter control, and electromagnetic interference performance. Therefore, the steadystate behavior of the pulse-width modulated (PWM) voltage source inverter (VSI) is widely studied. Describing the converter switching state with a switching function $s$, the impact of the PWM process on the voltages and currents can be described. Double Fourier integral analysis [3, 4], is used to derive the output voltage spectrum analytically. Assuming a constant DC link voltage and a sinusoidal input signal with constant modulation index $M$, the output voltage spectrum $u_{\mathrm{ac}}$ is derived as the multiplication of the phase leg switching functions $s$ and the half of the DC link voltage $u_{\mathrm{dc}} / 2$. Furthermore, the spectrum of the DC link current is developed in [2] using double Fourier integral analysis and in [8] by convolving the spectrum of the switching functions and the spectrum of the phase currents. In [11] an expression for the switching function spectrum for arbitrary bandlimited input signals is developed, which allows to incorporate harmonic input signals and overcomes the limitation to singlefrequency input signals.

With these methods the relationships of the converter voltages and currents are described accurately. However, the converter is connected to an electrical circuit of sources, loads, linear and nonlinear components. Forming a closed-loop system, the DC-side quantities influence the AC-side quantities, and vice versa. Therefore, all system equations have to be solved together, in order to cover the reactions.

Modeling the interaction of coupled-converter systems is a challenging task, due to the complexity of the system and the number of modeled effects. In [4] the harmonic and interharmonic behavior of a drive system of a passive rectifier and a VSI feeding an induction motor is studied in the time-domain. The coupling of all system quantities is covered, however it remains unclear if the equations are solved simultaneously and therefore covers any reactions. A closed-loop controlled DC/DC converter system is modeled in [12]. The harmonic interaction is covered in a matrix representation. However, a small-signal assumption is used for the harmonic interaction in the PWM process.
Solving the system equations in the frequency domain allows a direct solution for the steady state, which provides an additional tool for the engineer allowing a different view on the system. Moreover, the computing time can be lower than for time-domain simulations, as no transients are modeled. The harmonic domain is introduced as a subspace of the frequency domain, where only integer multiples of a fundamental frequency are defined. A system of non-linear equations describes the steady state with the harmonics as coupled variables. Solutions can be obtained by iterative methods that have been reported for various AC/DC converter systems [1].

Extensive studies have been published for AC/DC converter systems based on line-commutated converters [10] and use a convolution method to determine the AC/DC conversion and solve the system equations based on the Newton method.

The harmonic domain modeling has been adapted to a PWMVSI based STATCOM in [6] with a modulator model, which is an extension of a modulator model for a six-pulse thyristor bridge in [10]. In [9] a harmonic domain model for a single-phase and a three-phase VSI for photovoltaic systems is presented. Both publications use iterative solution methods. The switching function spectra are solved in the time domain, requiring the solution to be separated from the solution of the system equations.

In this paper, the harmonic domain model of the single-phase and three-phase VSI is derived. We show that for open-loop control the non-linearity of AC/DC conversion is simplified to a linear equation system by means of discrete convolution. The resulting equation system is linear, allowing a direct, non-iterative solution method. The models are easily extended to a coupled converter system.

\section{Model development}

\subsection{Model of one VSI phase leg}

The fundamental building block of a VSI is one inverter phase leg (one half bridge) (Fig. 1). The upper and lower IGBTs in each phase leg $v$ are switched comparatively. Assuming ideal switching behavior without interlocking time ("dead time"), each phase leg can be replaced by a single-pole double-throw switch with the switching function

$$
s_{v} \in\{-1,1\}
$$


The switching function is used to provide the algebraic connection of the AC-side voltage and current $\left(u_{\mathrm{ac}}, i_{\mathrm{ac}}\right)$ and the DC-side voltage and current $\left(u_{\mathrm{dc}}, i_{\mathrm{dc}}\right)$.

$$
\begin{gathered}
i_{\mathrm{dc} v}(t)=\frac{1}{2}\left(i_{\mathrm{dcp} v}(t)-i_{\mathrm{dcn} v}(t)\right)=\frac{1}{2} \cdot s_{v}(t) \cdot i_{\mathrm{ac} v}(t) \\
u_{\mathrm{ac} v}(t)=\frac{1}{2} \cdot s_{v}(t) \cdot u_{\mathrm{dc}}(t)
\end{gathered}
$$

Note that the DC-side current of a single half bridge is merely a fictive current. Transforming the equations to the harmonic domain yields a discrete convolution of the spectra for the calculation of the $k$-th harmonic of the fundamental angular frequency $\omega_{0}$ denoted with the subscript ', $k$ ':

$$
\begin{aligned}
& \underline{i}_{\mathrm{dc} v, k}=\left[\frac{1}{2} \cdot \underline{\boldsymbol{s}}_{v}(k) * \underline{\boldsymbol{i}}_{\mathrm{ac} v}(k)\right]_{, k}=\frac{1}{2} \cdot \sum_{m=-\infty}^{\infty} \underline{s}_{v, m} \cdot \underline{i}_{\mathrm{ac} v,(k-m)} \\
& \underline{u}_{\mathrm{ac}, k}=\left[\frac{1}{2} \cdot \underline{\boldsymbol{s}}_{v}(k) * \underline{\boldsymbol{u}}_{\mathrm{dc}}(k)\right]_{, k}=\frac{1}{2} \cdot \sum_{m=-\infty}^{\infty} \underline{s}_{v, m} \cdot \underline{u}_{\mathrm{dc} v,(k-m)}
\end{aligned}
$$

The spectrum of the switching function is represented in the vector $\underline{\boldsymbol{s}}_{v}(k)$ that contains the complex Fourier coefficients as the elements $\underline{s}_{\nu, k}$ :

$$
s_{v}(t)=\sum_{k=-\infty}^{\infty} \underline{s}_{v, k} \cdot \mathrm{e}^{\mathrm{j} k \omega_{0} t}
$$

In general, the convolution represents the coupling of the harmonics of the converter currents and voltages of $\mathrm{AC}$ and DC side.

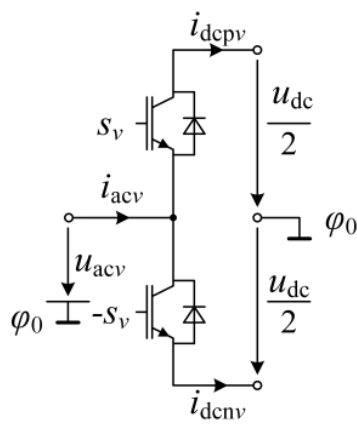

Fig. 1. One inverter phase leg

\subsection{Single-phase VSI model}

The single-phase VSI in Fig. 2 consists of two inverter phase legs (one full bridge). The inductance $L_{\mathrm{ac}}$ and the resistance $R_{\mathrm{ac}}$ represent a linear AC-side filter, and the capacitance $C_{\mathrm{dc}}$ and the resistance $R_{\mathrm{dc}}$ a linear DC-side filter. Disturbances (e.g. grid, machine or other converter) are incorporated by a voltage source $u_{\text {dis }}$ on the AC side and by a current source $i_{\text {dis }}$ on the DC side. The connection of the two phase legs yields

$$
\begin{aligned}
& i_{\mathrm{ac}}(t)=i_{\mathrm{ac} 1}(t)=-i_{\mathrm{ac} 2}(t) \\
& u_{\mathrm{ac}}(t)=u_{\mathrm{ac} 1}(t)-u_{\mathrm{ac} 2}(t),
\end{aligned}
$$

and the converter system equations are obtained by applying the equations of one inverter phase leg to the single-phase VSI:

$$
\begin{aligned}
i_{\mathrm{dc}}(t) & =\frac{1}{2} \cdot\left(s_{1}(t)-s_{2}(t)\right) \cdot i_{\mathrm{ac}}(t) \\
u_{\mathrm{ac}}(t) & =\frac{1}{2} \cdot\left(s_{1}(t)-s_{2}(t)\right) \cdot u_{\mathrm{dc}}(t)
\end{aligned}
$$

The linear AC-side and DC-side filters are described for each harmonic individually by their harmonic transfer functions with the AC-side impedance

$$
\underline{z}_{\mathrm{ac}, k}=\frac{1}{\underline{y}_{\mathrm{ac}, k}}=R_{\mathrm{ac}}+\mathrm{j} k \omega_{0} L_{\mathrm{ac}},
$$

and the DC-side admittance

$$
\underline{y}_{\mathrm{dc}, k}=\frac{1}{\underline{z}_{\mathrm{dc}, k}}=\frac{1}{R_{\mathrm{dc}}}+\mathrm{j} k \omega_{0} C_{\mathrm{dc}} .
$$

The complete converter system is described by the following four equations:

$$
\begin{gathered}
\underline{i}_{\mathrm{ac}, k}=y_{\mathrm{ac}, k} \cdot\left(\underline{u}_{\mathrm{dis}, k}-\underline{u}_{\mathrm{ac}, k}\right) \\
\underline{u}_{\mathrm{dc}, k}=\underline{z}_{\mathrm{dc}, k} \cdot\left(\underline{i}_{\mathrm{dis}, k}+\underline{i}_{\mathrm{dc}, k}\right) \\
\underline{i}_{\mathrm{dc}, k}=\left[\frac{1}{2} \cdot\left(\underline{\boldsymbol{s}}_{1}(k)-\underline{\boldsymbol{s}}_{2}(k)\right) * \underline{\boldsymbol{i}}_{\mathrm{ac}}(k)\right]_{, k} \\
=\frac{1}{2} \cdot \sum_{m=-\infty}^{\infty}\left(\underline{s}_{1, m}-\underline{s}_{2, m}\right) \cdot \underline{i}_{\mathrm{ac},(k-m)} \\
\underline{u}_{\mathrm{ac}, k}=\left[\frac{1}{2} \cdot\left(\underline{\boldsymbol{s}}_{1}(k)-\underline{\boldsymbol{s}}_{2}(k)\right) * \underline{\boldsymbol{u}}_{\mathrm{dc}}(k)\right]_{, k} \\
=\frac{1}{2} \cdot \sum_{m=-\infty}^{\infty}\left(\underline{s}_{1, m}-\underline{s}_{2, m}\right) \cdot \underline{u}_{\mathrm{dc},(k-m)}
\end{gathered}
$$

The equations (13) to (16) describe the system for one harmonic. Limiting the description to $k_{\max }$ harmonics, the vectors $\underline{\boldsymbol{u}}_{\mathrm{ac}}, \underline{\boldsymbol{i}}_{\mathrm{ac}}, \underline{\boldsymbol{u}}_{\mathrm{dc}}, \underline{\boldsymbol{i}}_{\mathrm{dc}}$ have the length $l=2 \cdot k_{\mathrm{max}}+1$. The equations can be used to eliminate three of the unknown spectra. Equation (17) gives the final equation for the $k$-th harmonic with $\underline{\vec{U}}_{\mathrm{dc}}$ as the remaining variable. $\boldsymbol{D}\left(\underline{\boldsymbol{y}}_{\mathrm{ac}}(k)\right)$ is a diagonal matrix with $\underline{y}_{\mathrm{ac}, k}$ as the $k$-th diagonal element.

$$
\begin{aligned}
& \underline{y}_{\mathrm{dc}, k} \underline{u}_{\mathrm{dc}, k}+ \\
& \frac{1}{4}\left[\left(\underline{\boldsymbol{s}}_{1}(k)-\underline{\boldsymbol{s}}_{2}(k)\right) * \boldsymbol{D}\left(\underline{\boldsymbol{y}}_{\mathrm{ac}}(k)\right)\left(\underline{\boldsymbol{s}}_{1}(k)-\underline{\boldsymbol{s}}_{2}(k)\right) * \boldsymbol{u}_{\mathrm{dc}}(k)\right]_{, k}= \\
& \underline{i}_{\mathrm{dis}, k}+\frac{1}{2}\left[\left(\underline{\boldsymbol{s}}_{1}(k)-\underline{\boldsymbol{s}}_{2}(k)\right) * \boldsymbol{D}\left(\boldsymbol{y}_{\mathrm{ac}}(k)\right) \boldsymbol{u}_{\mathrm{dis}}(k)\right]_{, k}
\end{aligned}
$$

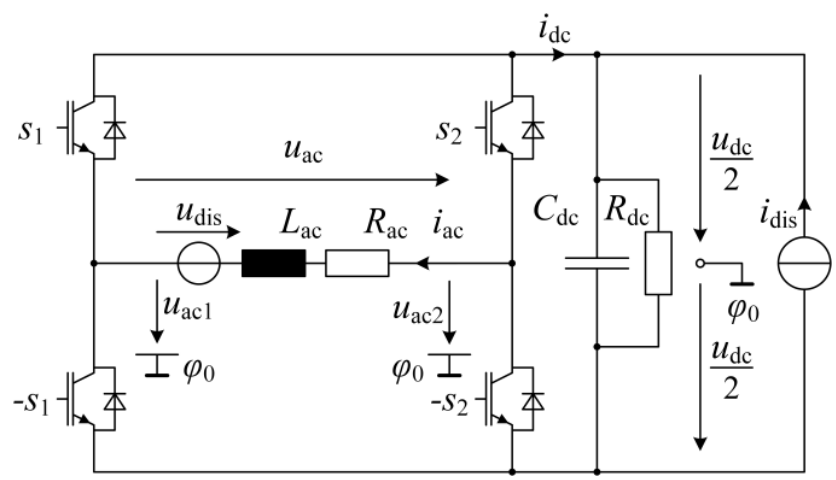

Fig. 2. Single-phase VSI

\subsection{Three-phase VSI model}

The three-phase VSI in Fig. 3 comprises three phase legs (three half-bridges).

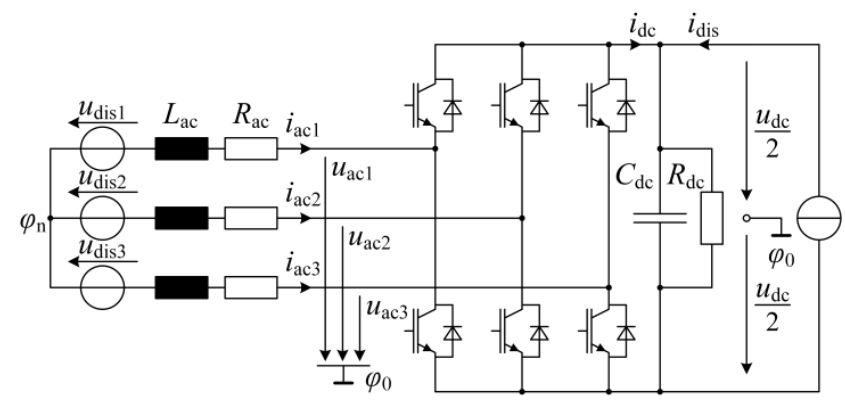

Fig. 3. Three-phase VSI 
The AC-side disturbance consists of three individual voltage sources connected to the neutral point $\varphi_{\mathrm{n}}$ Adapting the previous equations to the three phase legs, denoted with $v \in\{1,2,3\}$, yields:

$$
\begin{gathered}
i_{\mathrm{dc}}(t)=\frac{1}{2} \cdot \sum_{v=1}^{3} s_{v}(t) \cdot i_{\mathrm{ac} v}(t) \\
u_{\mathrm{ac} v}(t)=\frac{1}{2} \cdot s_{v}(t) \cdot u_{\mathrm{dc}}(t) \\
\underline{\vec{I}}_{\mathrm{dc}}=\frac{1}{2} \cdot \sum_{v=1}^{3} \underline{\vec{S}}_{v} * \underline{\vec{I}}_{\mathrm{ac} v} \\
\underline{\vec{U}}_{\mathrm{ac} v}=\frac{1}{2} \cdot \underline{\vec{S}}_{v} * \underline{\vec{U}}_{\mathrm{dc}}
\end{gathered}
$$

The relationship of the DC-side current and voltage is the same as for the single-phase VSI in (14). A symmetrical filter for a three-phase system has the form

$$
\underline{\boldsymbol{Y}}_{\mathrm{ac}, k}=\underline{y}_{\mathrm{ac}, k} \cdot \frac{1}{3}\left[\begin{array}{ccc}
2 & -1 & -1 \\
-1 & 2 & -1 \\
-1 & -1 & 2
\end{array}\right] .
$$

With $y_{\mathrm{ac}, k}$ defined in (11), the relationship of the AC-side currents and voltages can be denoted in vector form:

$$
\underline{\boldsymbol{i}}_{\mathrm{ac}, k}=\underline{\boldsymbol{Y}}_{\mathrm{ac}, k} \cdot\left(\underline{\boldsymbol{u}}_{\mathrm{dis}, k}-\underline{\boldsymbol{u}}_{\mathrm{ac}, k}\right)
$$

Higher order filters and unsymmetrical filters can be modeled by adapting the admittance matrix $\underline{\boldsymbol{Y}}_{\mathrm{ac}, k}$.

\subsection{Model for coupled VSI}

Connecting two converters A and B in the DC link (back-toback configuration) allows the coupling of two AC networks of different fundamental frequencies, e.g. a drive system with grid connection and variable speed drive. The DC-side current of converter $\mathrm{A}\left(i_{\mathrm{dcA}}\right)$ can be considered as the disturbance current of converter $\mathrm{B}$, and vice versa. In order to represent the interaction of both systems, the overall equation system has to be solved together using the coupling relationship of the DC link:

$$
\underline{y}_{\mathrm{dc}, k} \cdot \underline{u}_{\mathrm{dc}, k}=\underline{i}_{\mathrm{dcA}, k}+\underline{i}_{\mathrm{dcB}, k}
$$

The fundamental frequency of the overall system is the greatest common divisor of both systems' fundamental frequencies:

$$
f_{0}=\operatorname{gcd}\left(f_{0 \mathrm{~A}}, f_{0 \mathrm{~B}}\right)
$$

A connection of two converters on the AC side can be applied similarly by substituting the disturbance voltage of one system with the AC-side voltage of the other system.

\section{Solution method and results}

For an open-loop controlled converter, the modulator input is independent of the system variables. Therefore, the spectrum of the switching function $\underline{\boldsymbol{s}}_{v}$ can be calculated in advance. As it forms a discrete line spectrum, a discrete convolution results in no loss of accuracy. The switching spectrum can be seen as a set of parameters, and (17) becomes a linear equation.

Limiting the number of harmonics to $k_{\max }$, an approximation is performed, leading to a linear equation system $\underline{\boldsymbol{A}} \boldsymbol{x}=\underline{\boldsymbol{b}}$. The system matrix $\underline{\boldsymbol{A}}$ contains the linear transfer functions and the switching function spectrum, $\underline{x}$ comprises all harmonic variables, and $\underline{\boldsymbol{b}}$ includes the harmonics of the disturbances. All system variables are vectors with the length $l=2 \cdot k_{\max }+1$, as each harmonic is represented as complex Fourier coefficients with their positive and negative frequency components and the direct component.
The spectrum of the switching function is defined by the modulation process and described for various modulation methods in [7] using double Fourier integral analysis. The analysis assumes a pure sinusoidal input signal with a fixed modulation index $M$ in the linear control range (for PWM $0 \leq M \leq 1$ ). Symmetrical regularly sampled PWM yields the time domain expression of the switching functions, cf. [7]:

$$
\begin{aligned}
s_{\nu}(t) & =\frac{2}{\pi} \sum_{\substack{m=0 \\
m>0}}^{\infty} \sum_{\substack{n=1 \\
n=-\infty}}^{\infty} \frac{1}{q} J_{n}\left(q \frac{\pi}{2} M\right) \sin \left([q+n] \frac{\pi}{2}\right) \\
& \cdot \cos \left(m\left(\omega_{\mathrm{c}} t+\theta_{\mathrm{c}}\right)+n\left(\omega_{0} t+\theta_{0}\right)\right)
\end{aligned}
$$

$J_{n}(\xi)$ is the n-th order Bessel function with the argument $\xi$, $q=m+n \frac{\omega_{0}}{\omega_{\mathrm{c}}}, \omega_{0}$ and $\omega_{\mathrm{c}}$ are the fundamental and the carrier angular frequency, and $\theta_{0}$ and $\theta_{c}$ are the fundamental and the carrier phase shift, respectively.

The VSI models use the spectrum of the switching function. Therefore, the complex Fourier coefficients $\underline{s}_{v, k}$ of the switching function are obtained by converting (26) in the form of (6). [7] also provides the Fourier representation using real coefficients $\left(a_{k}, b_{k}\right)$ that can be transformed to the complex representation.

\subsection{Single-phase VSI}

Using the equations (13) to (16), the single-phase VSI (Fig. 2) can be described as the linear equation system $\underline{\boldsymbol{A}} \underline{\boldsymbol{x}}=\underline{\boldsymbol{b}}$ :

$$
\left[\begin{array}{cccc}
\boldsymbol{E} & \mathbf{0} & \boldsymbol{H} & \mathbf{0} \\
\boldsymbol{E} & \boldsymbol{D}\left(\underline{\boldsymbol{z}}_{\mathrm{ac}}\right) & \mathbf{0} & \mathbf{0} \\
\mathbf{0} & \mathbf{0} & \boldsymbol{D}\left(\underline{\boldsymbol{y}}_{\mathrm{ac}}\right) & -\boldsymbol{E} \\
\mathbf{0} & \boldsymbol{H} & \boldsymbol{E} & \mathbf{0}
\end{array}\right]\left[\begin{array}{c}
\underline{\boldsymbol{u}}_{\mathrm{ac}} \\
\underline{\boldsymbol{i}}_{\mathrm{ac}} \\
\underline{\boldsymbol{u}}_{\mathrm{dc}} \\
\underline{\boldsymbol{i}}_{\mathrm{dc}}
\end{array}\right]=\left[\begin{array}{c}
\mathbf{0} \\
\underline{\boldsymbol{u}}_{\mathrm{dis}} \\
-\underline{\boldsymbol{i}}_{\mathrm{dis}} \\
\mathbf{0}
\end{array}\right]
$$

All elements of the matrix $\boldsymbol{A}$ are submatrices of the size $l \times l$. The convolution matrix $\boldsymbol{H}$ is defined as the matrix that describes the convolution as a matrix multiplication

$$
\underline{\boldsymbol{H}} \underline{\boldsymbol{u}}=\frac{1}{2}\left(\underline{\boldsymbol{s}}_{1}-\underline{\boldsymbol{s}}_{2}\right) * \underline{\boldsymbol{u}}
$$

$\boldsymbol{E}$ denotes the identity matrix, $\mathbf{0}$ is the zero matrix and $\boldsymbol{D}($.$) is$ a diagonal matrix. The convolution matrix $\boldsymbol{H}$ can be easily implemented in Matlab using the function convmtx, resulting in a matrix of size $(2 l-1) \times l$, where the convolution matrix $\boldsymbol{H}$ is the centered submatrix of size $l \times l$. The resulting block diagram of the open-loop controlled converter is given in Fig. 4.

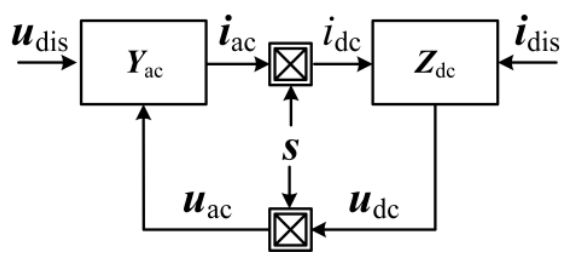

Fig. 4. Block diagram for an open-loop controlled VSI

Using (17) would result in a more compact description of the system, which can effect the numerical inversion to perform $\boldsymbol{x}=\boldsymbol{A}^{-1} \mathrm{~b}$.

Fig. 5 shows the results for the parameters of the system given in Table 1. The modulation index has been chosen to $M=0.4$ with zero phase shift between the fundamental components of $u_{\text {dis }}$ and the modulator input $\left(\theta_{0}=0\right)$. Disturbances are applied with $u_{\text {dis }}=40 \mathrm{~V} \sin \left(\omega_{0} t\right)+4 \mathrm{~V} \sin \left(11 \omega_{0}\right)$ and $i_{\text {dis }}=10 \mathrm{~A}+$ $2 \mathrm{~A} \sin \left(6 \omega_{0} t\right)$. The harmonic domain model considers 200 harmonics $\left(k_{\max }=200\right)$. The results of the analytical model in black are compared to results of a time-domain simulation in Simulink/Plecs in red, which are the Fourier coefficients of one fundamental period of the time-domain signals after all transients being completed. There is a good agreement of both models' results. 
Table 1. Styles predefined in IAPGOS template

\begin{tabular}{|c|c|c|}
\hline Parameter & Symbol & Value \\
\hline AC-side inductance & $L_{\mathrm{ac}}$ & $17.5 \mathrm{mH}$ \\
\hline AC-side resistance & $R_{\mathrm{ac}}$ & $300 \mathrm{~m} \Omega$ \\
\hline DC-side capacitance & $C_{\mathrm{dc}}$ & $480 \mu \mathrm{F}$ \\
\hline DC-side resistance & $R_{\mathrm{dc}}$ & $18 \Omega$ \\
\hline Fundamental frequency & $f_{0}$ & $50 \mathrm{~Hz}$ \\
\hline Carrier frequency & $f_{\mathrm{c}}$ & $1.5 \mathrm{kHz}$ \\
\hline
\end{tabular}
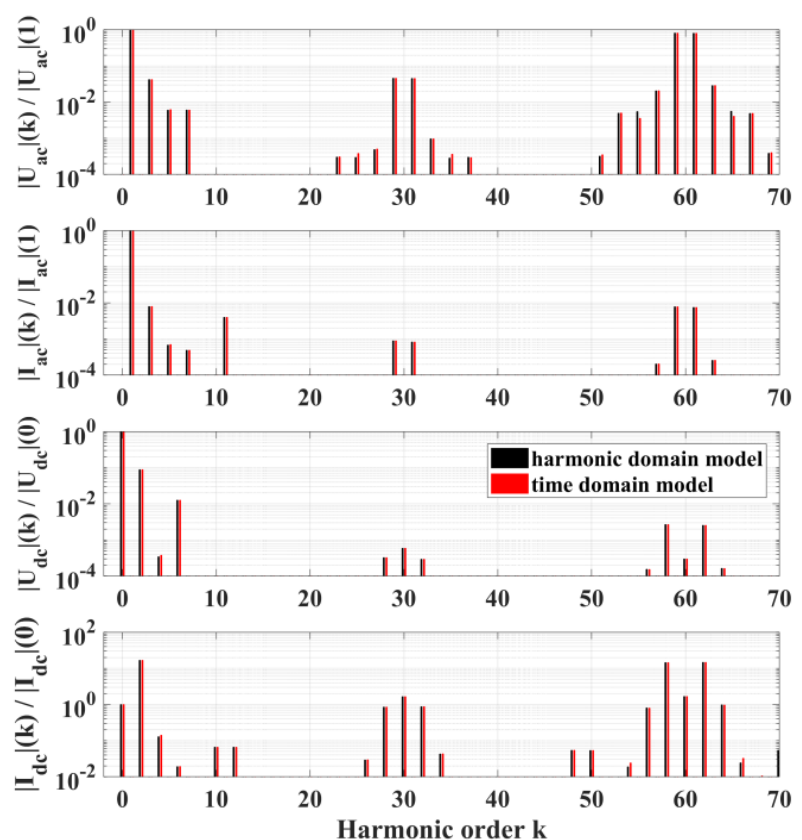

Fig. 5. Comparison of harmonic domain model (black) and time domain simulations (red) for a single-phase VSI

\subsection{Three-phase VSI}

For a three-phase VSI the solution method is merely an adaption to the three-phase system. Unsymmetrical filter and disturbance voltages can be applied in the model.

Fig. 6 provides a comparison of the proposed harmonic domain model, time domain simulations in Simulink/Plecs, and experimental results. The parameters of the system are the same as for the single-phase VSI in Table 1. The modulation index is set to $M=1$. A second converter system is used to generate the symmetrical three-phase disturbance voltage with a RMS line-line voltage of $40 \mathrm{~V}$. A phase-locked loop (PLL) assures no phase shifting between the fundamental components of $u_{\mathrm{dis}}$ and the modulator input $\left(\theta_{0}=0\right)$. There is no influence of the PLL in the steady-state behavior.
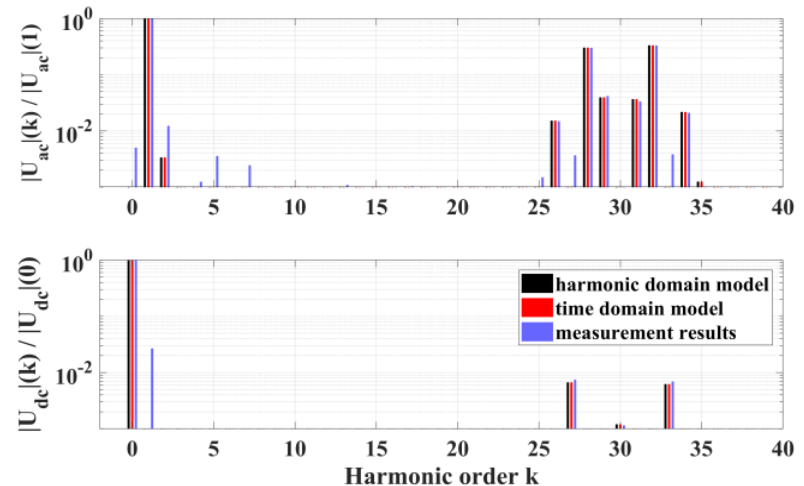

Fig. 6. Comparison of harmonic domain model (black), time domain simulations (red), and measurement results (blue) for a three-phase VSI
The harmonic domain model (black) and the time domain simulations (red) show a good conformity. There is no interlocking time modeled in both cases, which causes the deviations from the experimental results (blue), where an interlocking time is mandatory. The effects can be modeled using the approach presented in [5]. This leads to a dependency of the switching function on the phase leg current and therefore to a nonlinear equation system.

\subsection{Back-to-Back VSI}

Two single-phase VSI are connected in a common DC link to show the interaction of converter systems. System A has a fundamental frequency of $f_{0 \mathrm{~A}}=50 \mathrm{~Hz}$ and system B a fundamental frequency of $f_{0 \mathrm{~B}}=40 \mathrm{~Hz}$. For this purpose, the overall fundamental frequency is chosen to $10 \mathrm{~Hz}$. Fig. 7 compares the harmonic domain model with time domain simulations. For clarity only the first 25 harmonics are shown. The single-phase- VSI of system A creates a strong $100 \mathrm{~Hz}$ component in the DC link, which is passed on to system B as the interharmonic of $2 \cdot f_{0 \mathrm{~A}}-f_{0 \mathrm{~B}}=60 \mathrm{~Hz}$ (and $2 \cdot f_{0 \mathrm{~A}}+$ $f_{0 \mathrm{~B}}=120 \mathrm{~Hz}$ ). The propagation back to the DC link is visible as $20 \mathrm{~Hz}$ (and $100 \mathrm{~Hz}$ ). Besides other harmonics and interharmonics a $30 \mathrm{~Hz}$ and $70 \mathrm{~Hz}$ component can be explained. Again, there is a good accordance of the harmonic domain and time domain models.
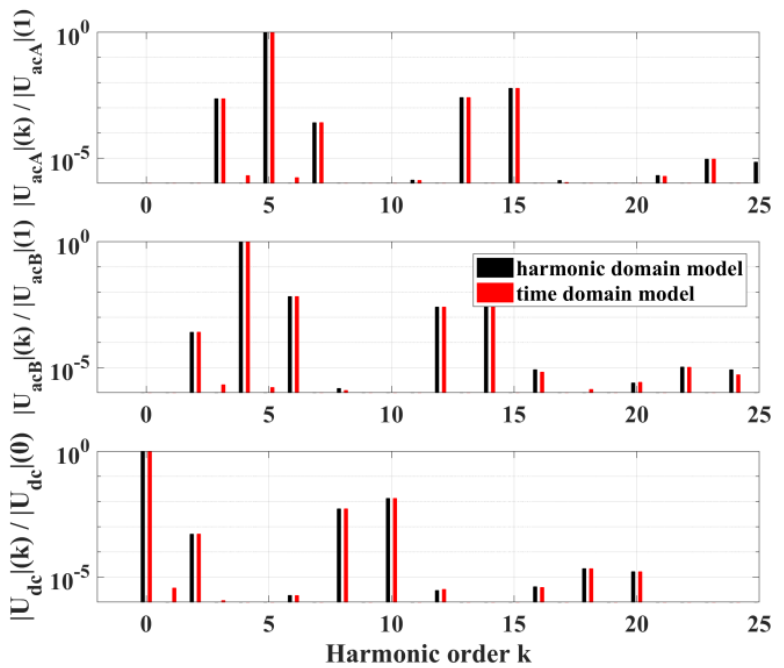

Fig. 7. Comparison of harmonic domain model (black) and time domain simulations (red) for two single-phase VSI in back-to-back configuration

\section{Conclusions}

As the fundamental building block of voltage source inverters, the phase leg has been analyzed in the harmonic domain and used to build models for the single- and the three-phase VSI. Applying open-loop control, the switching function spectrum is independent of the system variables. The outcome is a straightforward and quickly computable model for the steady-state spectrum, as the system equations become linear.

Whenever the switching function is dependent of the system variables, the equation system is non-linear, and an algorithm for non-linear equation systems is required, e.g. the Newton method. This includes modeling the interlocking time or closed-loop control. Moreover, the load, filters and disturbances can be nonlinear or dependent on the system variables, requiring iterative solution methods.

The analytical models of single VSI can be adapted to arbitrarily coupled converter systems to analyze the harmonic interaction of the subsystems. 


\section{Acknowledgements}

The authors would like to thank the Volkswagen Foundation for the financial support of this work within the project AMSES (Aggregated Models for the Simulation of Electromechanical Power Systems).

\section{References}

[1] Arrillaga J., Watson N.R.: The Harmonic Domain revisited. 13th International Conference on Harmonics and Quality of Power, 2008.

[2] Bierhoff M.H., Fuchs F.W.: DC-Link Harmonics of Three-Phase VoltageSource Converters Influenced by the Pulsewidth-Modulation Strategy-An Analysis. IEEE Transactions on Industrial Electronics. 55(5)/2008, 2085-2092.

[3] Black H.S.: Modulation Theory. Van Nostrand, Princeton 1953.

[4] Chang G.W., Chen S.K., Su H.J., Wang P.K.: Accurate Assessment of Harmonic and Interharmonic Currents Generated by VSI-Fed Drives Under Unbalanced Supply Voltages. IEEE Transactions on Power Delivery 26(2)/2011, 1083-1091.

[5] Chierchie F., Stefanazzi L., Paolini E.E., Oliva A.R.: Frequency Analysis of PWM Inverters With Dead-Time for Arbitrary Modulating Signals. IEEE Transactions on Power Electronics 29(6)/2014, 2850-2860.

[6] Collins C.D., Bathurst G.N., Watson N.R., Wood A.R.: Harmonic domain approach to STATCOM modelling. Transmission and Distribution IEE Proceedings - Generation 152(2)/2005, 194-200.

[7] Holmes G., Lipo T.A.: Pulse Width Modulation for Power Converters Principles and Practice. Wiley-IEEE Press, 2003.

[8] McGrath B.P., Holmes D.G.: A General Analytical Method for Calculating Inverter DC-Link Current Harmonics. IEEE Transactions on Industry Applications 45(5)/2009, 1851-1859.

[9] Nduka O.S., Pal B.C.: Harmonic Domain Modeling of PV System for the Assessment of Grid Integration Impact. IEEE Transactions on Sustainable Energy 8(3)/2017, 1154-1165.

[10] Smith B.C., Watson N.R., Wood A.R., Arrillaga J.: Steady state model of the AC/DC convertor in the harmonic domain. IEE Proceedings - Generation, Transmission and Distribution 142(2)/1995, 109-118.

[11] Song Z., Sarwate D.V.: The frequency spectrum of pulse width modulated signals. Signal Processing 83(10)/2003, 2227-2258

[12] Yue X., Zhuo F., Yang S., Pei Y., Yi H.: A Matrix-Based Multifrequency Output Impedance Model for Beat Frequency Oscillation Analysis in Distributed Power Systems. In IEEE Journal of Emerging and Selected Topics in Power Electronics 4(1)/2016, 80-92.
M.Sc. Eng. Malte John

e-mail: malte.john@ial.uni-hannover.de

Malte John received the Dipl.-Ing. from Leibniz Universität Hannover, Germany, in 2014.

Since 2014 he has been a Ph.D. student at the Institute for Drive Systems and Power Electronics, Lebniz Universität Hannover, Germany. His main research interests includes the modeling of harmonic interactions of power electronic systems.

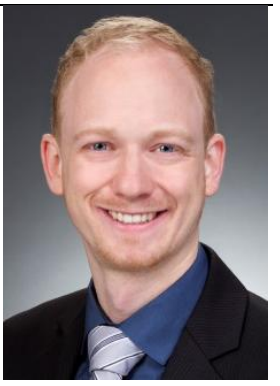

Prof. Axel Mertens

e-mail: mertens@ial.uni-hannover.de

Axel Mertens (S'89-M'92) received the Dipl.-Ing. and Dr.-Ing. (Ph.D.) degrees from RheinischWestfaelische Technische Hochschule (RWTH) Aachen University, Germany, in 1987 and 1992, respectively. From 1993 to 2004, he was with Siemens Drive Technologies, Germany. In 2004, he was appointed Professor of power electronics and drives at Leibniz Universität Hannover, Germany. Since 2012, he has been the Head of the Department Converter Technology within the Fraunhofer Institute for Wind Energy and Energy System Technology (IWES).

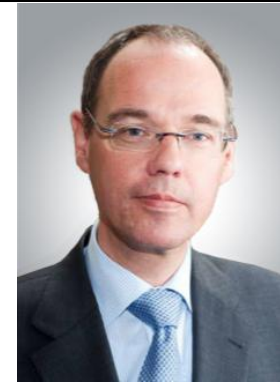

otrzymano/received: 08.12.2017 przyjęto do druku/accepted: 11.05 .2018 